\title{
Democracia, participação e deliberação. Contribuições ao debate sobre possíveis transformações na esfera democrática
}

Alfredo Alejandro Gugliano*

Neste artigo discuto a relação entre democracia, participação e deliberação. Com este objetivo o trabalho foi dividido em quatro tópicos: a democracia e seus adjetivos; a proposta habermasiana de procedimentos de deliberação discursivos; a contribuição das democracias participativas para o debate sobre a teoria da democracia e, por fim, a perspectiva de ampliação dos sentidos do conceito de democracia. Deste modo pretendo colaborar para a expansão de uma vertente de estudos sobre a questão democrática que, além de enfatizar aspectos vinculados ao sistema de eleição de lideranças, também analisa a qualidade do processo democrático. Este é um dos temas centrais das ciências sociais contemporâneas considerando que, conflitos como os assistidos em algumas regiões da América Latina, África e no Golfo Pérsico, alimentam dúvidas sobre a capacidade de expansão da simbiose entre capitalismo e democracia para outras regiões afora as sociedades ocidentais complexas, sobrando incertezas sobre a capacidade de esta articulação oferecer

* Professor do Instituto de Sociologia e Política da Universidade Federal de Pelotas e pesquisador do CNPq. E-mail: aag@ufpel.edu.br

\begin{tabular}{|l|l|l|l|l|l|} 
Civitas & Porto Alegre & v. 4 & n. 2 & jul.-dez. 2004 & p. 257-283
\end{tabular}


benefícios frente ao atual processo de deterioração física, cultural, social e ambiental do planeta. ${ }^{1}$

A perspectiva de análise política qualitativa tem sido explorada por uma ampla gama de autores que, entre diversas problemáticas, investigam as trajetórias das novas democracias fundadas a partir da segunda metade dos anos setenta no sul da Europa, América Latina, Leste da Europa e, mais recentemente, na África e na Ásia. ${ }^{2}$ Estas experiências, agrupadas por Samuel Huntington (1994) na chamada terceira onda de democratizações, foram marcadas por um contexto no qual a reorganização da cidadania e dos direitos civis conviveu com o fenômeno do neoliberalismo e a tentativa de submeter, principalmente, as políticas sociais do Estado às necessidades advindas das relações econômicas de mercado.

Diferentemente de uma conjuntura centrada na iniciativa de o Estado construir um projeto nacional de desenvolvimento que, no período pós-1945, pautou as democracias sob o prisma ou do bem-estar social europeu ou do populismo latino-americano, a reconstrução dos regimes democráticos levada a cabo pela maior parte das novas democracias pode ser contextualizada através de circunstâncias particulares nas quais as próprias estruturas estatais foram colocadas no banco dos réus sob a acusação de anacrônicas e ineficientes. Como é sabido, este não foi um fenômeno exclusivamente regional, mas um reflexo de um amplo processo de reconstrução dos pilares que, pelo menos desde a Ilustração, haviam sustentado a organização das sociedades ocidentais, evento gerado a partir da expansão do que vem sendo definido como globalização. ${ }^{3}$

1 A problemática relação entre capitalismo e democracia é tema de um número considerável de obras acadêmicas, entre as quais destaco as abordagens centradas na idéia de "risco" como, por exemplo: Beck, 1992.

2 Uma das características mais interessantes dos trabalhos sobre as novas democracias é a ênfase nos problemas que boa parte das mesmas vêm enfrentando no processo de consolidação do regime. Sobre o tema existe uma extensa literatura como, por exemplo, os artigos presentes em Cherensky e Pousadela, 2001.

3 Boa parte das principais discussões a respeito das diferentes caracterizações sobre a globalização podem ser encontradas na sintética descrição apresentada em Held e McGrew, 2000. 
O ocaso da esfera de influência do Estado-nação é um fenômeno discutível na medida em que inclusive em episódios radicais de desestatização - como, por exemplo, no caso do então Presidente Carlos Saul Menem, que privatizou o espaço radioelétrico argentino $(1997)^{4}$-, o mesmo mantém uma estrutura de regulação de uma série de relações em nível nacional. Contudo, é inquestionável que, com raras exceções, o tempo do estadocentrismo acabou e o Estado perdeu grande parte de sua capacidade de centralização social (Habermas, 2002, p. 138-142).

Além disso, o desmoronamento político, econômico e cultural do comunismo ou do socialismo realmente existente - como preferem dizer os marxistas críticos - interferiu diretamente na expansão numérica das democracias ocidentais enquanto forma e expressão do modo capitalista de organização social, quer dizer, um crescimento centrado na idéia de que era função da democracia apoiar, independente das conseqüências, a difusão da economia de mercado (Gugliano, 2004). Esta foi uma idéia notadamente presente na transição do comunismo ao capitalismo vivenciado no Leste Europeu, onde as perdas sociais sofridas por populações acostumadas a sociedades nas quais existia uma estrutura administrativa funcional em termos de políticas sociais foram apresentadas, pelos novos gestores democráticos, como uma conseqüência natural do ingresso na modernidade (Gaspard, 1993).

As conseqüências destas mudanças estão longe de serem uniformes. Como destaca Anthony Giddens (2000, p. 23), que emprega a feliz expressão de "um mundo em descontrole":

A globalização não é portanto um processo singular, mas um conjunto complexo de processos. E estes operam de maneira contraditória ou antagônica. A maioria das pessoas pensa que a globalização está simplesmente 'retirando' poder ou influência de comunidades locais e nações para transferi-lo para a arena global. E realmente esta é uma de suas conseqüências. Contudo, ela tem também o efeito oposto. A globalização não somente puxa para cima, mas também empurra para baixo, criando novas pressões por autonomia local.

Precisamente num contexto especial como este, é oportuno repensar o papel que a democracia cumpre na organização política da sociedade e sua perspectiva de ampliação na direção de abranger questões sociais extra-eleitorais, tema que desenvolvo nas páginas a seguir.

4 Esta foi uma das medidas revertidas, no início de 2004, com a re-estatizaçao levada a cabo pela atual Presidente da Argentina, Nestor Kirchner. 


\section{A democracia e seus adjetivos}

Tradicionalmente, a maioria dos autores que analisam o desenvolvimento das sociedades contemporâneas considera a democracia enquanto um regime ou sistema político baseado num conjunto de normas prescritas para governantes e eleitores que visam regulamentar a escolha dos segmentos que deverão, por período previamente acordado, gerir a estrutura do Estado. As origens desta caracterização são difíceis de resgatar, porém, costumeiramente se indica Joseph Schumpeter (1963) como o fundador de uma perspectiva analítica que considera a democracia unicamente como a forma através da qual os cidadãos elegem seus governantes por meio do que ele identificou como o principal método democrático, isto é, o voto. Dentro deste horizonte, Giovanni Sartori (1994) apresenta uma extensa argumentação sobre a existência de diversas caracterizações sobre o que é a democracia e a forma como, devido a esta abundância de significados, elas contribuem para confundir a definição deste conceito, preferindo delimitar a democracia, como fizeram Schumpeter e outros, à esfera política da sociedade:

Se o sistema principal, o sistema político global, não é um sistema democrático, então a democracia social tem pouco valor, a democracia industrial tem pouca autenticidade e a igualdade econômica pode não diferir da igualdade entre os escravos. Esta é a razão pela qual a "democracia" sem adjetivos significa "democracia política", a razão pela qual a democracia é antes de tudo um conceito político [...]" (Sartori, 1994. cit., p. 28-29).

O formalismo presente nas argüições dos defensores de uma democracia a secas acaba colocando o debate sobre a questão num labirinto no qual a saída coincide com a porta de ingresso a um novo labirinto, considerando que identificar a democracia somente como expressão de determinadas formas de organização política auxilia a ocultar o modo como a democracia realmente funciona, privilegiando o plano da aparência em contraposição ao da essência desta experiência.

Um dos temas mais recorrentes da história da filosofia, a dicotomia entre essência e aparência foi utilizada, entre outros, por Karl Marx (1977), como uma forma de demonstrar as transformações da mercadoria no sistema capitalista que, apesar de ser apresentada a partir do seu valor de uso - 
a sua aparência - carrega em si mesma também um valor de troca - a sua essência - que, no final das contas, acabará determinando o papel que a mesma ocupará na hierarquia das transações econômicas de mercado. Transferindo esta percepção para o campo das relações sociais, Herbert Marcuse desenvolveu uma contundente crítica à maneira como as análises sociais vinham contribuindo para a mistificação da sociedade capitalista, apreciada pelos funcionalistas apenas desde uma perspectiva evolucionista, e apelou para a necessidade de repensar o papel das ciências sociais:

Contra essa nova mistificação, que transforma a racionalidade em seu oposto, deve ser sustentada a distinção. [...] O problema está no fato de a estatística, as medições e os estudos locais da Sociologia empírica e da Ciência Política não serem suficientemente racionais. Tornam-se mistificadores no quanto são isolados do contexto verdadeiramente concreto que faz os fatos e determina sua função. Este contexto é maior do que o das fábricas e das oficinas investigadas, das cidades e vilas estudadas, dos setores e grupos cuja opinião pública é sondada ou cuja probabilidade de sobrevivência é calculada e diferente dele. [...] Este contexto real no qual os sujeitos particulares obtêm sua significação real só é definível dentro de uma teoria da sociedade. Isso porque os fatores dos fatos não são dados imediatos da observação, da medição e da interrogação. Esses só se tornam dados numa análise capaz de identificar a estrutura que mantém juntas as partes e os processos da sociedade e que determina a sua inter-relação (Marcuse, 1967, p. 180).

Afirmar que uma significativa parte dos autores que analisam o tema da democracia privilegia abordar a aparência deste conceito não significa que esta seja uma dimensão inexistente. Mesmo diferenciando-se em termos do sistema eleitoral, partidário ou de governo, as democracias possuem uma série de requisitos legais que as identificam independentemente do país no qual elas se desenvolvem ou das tradições culturais que determinados povos possuem. Genericamente, estas características giram em torno de pré-condições eleitorais que possibilitam aos cidadãos elegerem seus governantes e serem eleitos: a liberdade de imprensa e organização (social, partidária, etc.), a regulamentação do direito ao voto; a autonomia dos poderes (executivo, legislativo e judiciário), entre outros (Bobbio, 1995, p. 326-329). 
Contudo, a existência de uma estrutura política democrática nem sempre é garantia de que todos os cidadãos vivam debaixo do teto de uma democracia. Por exemplo, fenômenos como o do absenteísmo eleitoral, que afeta praticamente todos os países nos quais o voto é facultativo, demonstram o grande distanciamento existente entre os eleitores e as personagens que compõem os espectro político-partidário e postulam cargos públicos, fato que, se não gera uma crise de legitimidade da democracia, sim provoca uma crise de identidade na medida em que os cidadãos não se reconhecem enquanto partícipes da esfera pública. ${ }^{5}$ Para ilustrar esta falta de interesse frente às eleições um caso interessante é o dos Estados Unidos da América, onde os índices de abstenção eleitoral são significativos.

\section{Gráfico 1}

Abstenção nas Eleições Presidenciais

nos Estados Unidos da América (1946-2000)

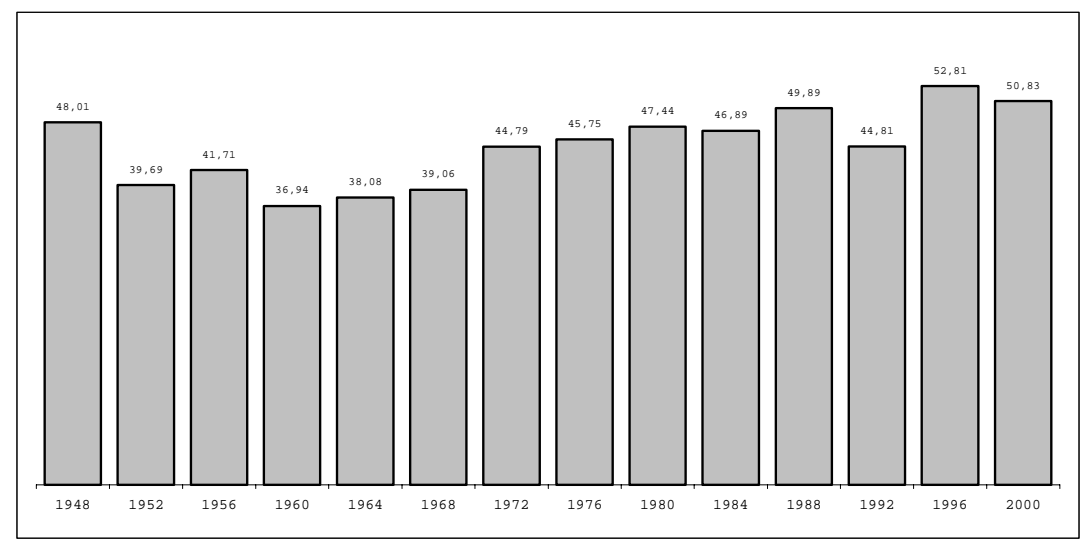

Fonte dos dados: Pintor e Gratschew, 2001.

5 A caracterização da crise de identidade enquanto uma incapacidade dos indivíduos se verem enquanto parte de um grupo tem sua origem na psicologia social desenvolvida a partir dos estudos do Círculo de Viena e, especialmente, de Erik Erikson e suas investigações sobre a crise de identidade dos adolescentes. Sobre o tema ver Erikson, 1968. 
Referindo-se às conseqüências do absenteísmo estadunidense, Renato Janine Ribeiro (2003, p. 170-171) é enfático na afirmação de que:

Nos Estados Unidos, onde o voto é facultativo, não só a abstenção nas eleições tem sido bastante grande, como ela tende a se perpetuar nos mesmos grupos sociais étnicos - basicamente os dos discriminados socialmente, em especial, os negros. Ora, segundo a discussão política que atualmente chega à própria mídia, esse fenômeno estaria agravando a desigualdade, na medida em que: 1) os negros votam menos que os brancos, portanto 2) os eleitos procuram atender mais os interesses dos seus reais eleitores do que aos dos não-votantes; de modo que 3) a exclusão social dos negros aumenta e, com isso 4) mantém-se ou se acentua a abstenção eleitoral dos negros.

Assim, as barreiras econômicas e sociais criadas a partir de situações que ampliam a desigualdade acabam impedindo que extensos segmentos de cidadãos exerçam seus direitos com plenitude. Como bem apontou um pioneiro estudo de Amartya Sen (2000), no qual o autor questiona uma concepção de desenvolvimento exageradamente vinculada aos resultados dos indicadores econômicos, a expectativa de vida de extensos segmentos da população de países considerados ricos nem sempre é mais elevada do que a de países do Terceiro Mundo, na medida em que, mesmo sendo estes habitantes de sociedades privilegiadas não possuem condições mínimas de usufruir daquilo que suas sociedades oferecem.

Um raciocínio semelhante pode ser realizado no que diz respeito à nossa compreensão da democracia, considerando que a existência de uma série de requisitos, instituições, leis, etc., não necessariamente impedem que extensos segmentos da população fiquem alijados do sistema democrático. Desde este prisma questões como a cultura, as relações de gênero, a violência, as opções religiosas, a pobreza, etc., não somente podem interferir na forma como as pessoas votam, como também na dinâmica de funcionamento dos governos democráticos.

Em termos conceituais, a caracterização da democracia apenas enquanto um regime político impede uma compreensão maior do problema, restringindo a questão ao campo da dominação social na medida em que, seguindo a ótica weberiana, o Estado - núcleo de articulação entre burocratas, juristas e políticos - é o elemento central de legitimação dos mecanismos de dominação social através da aceitação da validade legal das suas intervenções. 
A partir deste mesmo ângulo, Charles Tilly (1992, p. 20) define o Estado como uma organização coercitiva que tem o poder de prevalecer sobre a maior parte das outras organizações no interior de um território com dimensões específicas. Com este fim, mais do que mecanismos de dominação implícitos, o que caracteriza o Estado é precisamente a sua capacidade de, sem perder a legitimidade, impor à força o cumprimento de suas determinações. Como afirmou Max Weber (1993, p. 1056),

[...] o Estado moderno sociologicamente só pode ser definido, em última instância, a partir de um instrumento específico que, da mesma forma do que todas as associações políticas, lhe é próprio, a saber: a coerção física. [...] Por certo, a coerção não é de modo algum o meio normal e único do Estado - [...] -, porém é seu meio específico.

Outro problema da limitação da democracia exclusivamente à esfera do Estado é que deixa de lado um conjunto de elementos que fazem parte do mercado econômico e se relacionam diretamente com a infra-estrutura da sociedade. Isto faz com que o coletivo de organizações que determinam as suas atividades a partir da produção, comercialização e transação de bens com valor monetário, fiquem preservadas de aplicar qualquer tipo de prerrogativa democrática na sua forma de gestão ou planejamento estratégico dos seus objetivos. Deste modo, mesmo no caso de organizações econômicas que têm a sua matriz ou corpo administrativo central localizado em países democráticos, a busca de competitividade e a necessidade de expansão das ganâncias fazem com que seja utilizado um conjunto de métodos que, como bem lembrou Vivianne Forrester, representam as ações de um novo tipo de ditadura: a imposição do predomínio do lucro privado sobre os interesses de bem-estar de grandes contingentes da população. ${ }^{6}$

Ao se retirar o mercado econômico do âmbito de alcance da gestão democrática, também se consolida a separação entre o público, mediado pelo Estado democrático de direito, e o privado, onde predomina a ausência de limites na busca da satisfação (econômica) individual. Dito de outra forma, este afastamento abre espaço para o desenvolvimento de formas extremas de atividade econômica que fogem dos padrões éticos e morais das sociedades contemporâ-

6 Cabe ainda agregar que esta forma de ditadura também se expressa nas condições de trabalho que imperam em organizações econômicas e nas formas de trabalho desumanas e autoritárias que predominam, por exemplo, em muitas das fábricas terceirizadas situadas nas zonas de livre-comércio. 
neas (tráfico de escravos/escravas sexuais; comércio de órgãos, narcotráfico, pedofilia, etc.) que, no final das contas, são representações do mercado econômico mesmo que em condições de contravenção.

Apesar das controvérsias, é evidente a existência de elos de ligação entre um mercado econômico ilegal desenvolvido às margens da sociedade e outro legal, desenvolvido em estabelecimentos considerados respeitáveis. Como descreve Jorge Beinstein (2001, p. 140):

[...] a seqüência de crescentes lucros dos sistemas de produção central para a periferia, passando pelas transferências de indústrias e a especulação financeira, tem um último elo. $\mathrm{O}$ dos 'negócios ilegais', que abarcam um conjunto muito variado de atividades de distintos níveis de criminalidade como o narcotráfico e a lavagem de fundos, o tráfico de armas, as redes de prostituição, o tráfico de bebês, a "proteção", a espionagem industrial, o contrabando, a venda fraudulenta de bens e serviços ao Estado, etc.

A caracterização da democracia apenas enquanto uma forma de governo trás vantagens quando do que se trata é da diferenciação frente a regimes políticos autoritários, questão sobre a qual existe uma abundante literatura relacionada com o estudo dos processos de transição vividos, entre os anos 70 e 90, na América Latina e no Leste/Sul da Europa. Porém, esta mesma caracterização perde potência quando a necessidade é a de avaliar o funcionamento e a eficiência das democracias. Em especial, noções como as de democracia com "alta intensidade" e com "baixa intensidade" foram utilizadas, com maior ou menor êxito, para explicar possíveis falhas do sistema democrático e sua convivência com altos índices de pobreza ou corrupção política, para citar apenas alguns exemplos, terminologia que não impede que, a cada ano que passa, cresçam as barreiras que afastam os eleitores dos políticos profissionais.

Este é um aspecto importante que vem sendo sublinhado pela literatura especializada: o surgimento de um sentimento de distanciamento entre os cidadãos e seu sistema político que, muitas vezes, passa a ser visto com desconfiança ou desprezo. Para Mariano Torcal (2000, p. 234), nas sociedades atuais se dissemina uma postura de desafeição frente à política, entendendo este conceito como a expansão de um "[...] sentimento subjetivo de ineficácia, cinismo, e falta de confiança no processo político, nos políticos e instituições democráticas, gerando distanciamento e alienação, mas não questionando a legitimidade do regime político". 
No caso da América Latina, os dados referentes a estudos sobre a cultura e os valores políticos vêm demonstrando que, apesar de já terem passado mais de duas décadas desde o fim da maioria das ditaduras militares na região, ainda é frágil o apoio à democracia por parte dos cidadãos latinoamericanos, sendo que o contingente dos mesmos que ou é indiferente ao tipo de regime político do seu país ou é francamente favorável ao retorno das ditaduras militares é bastante considerável.

\section{Gráfico 2}

Opinião dos latino-americanos sobre o regime político dos seus países (\%)

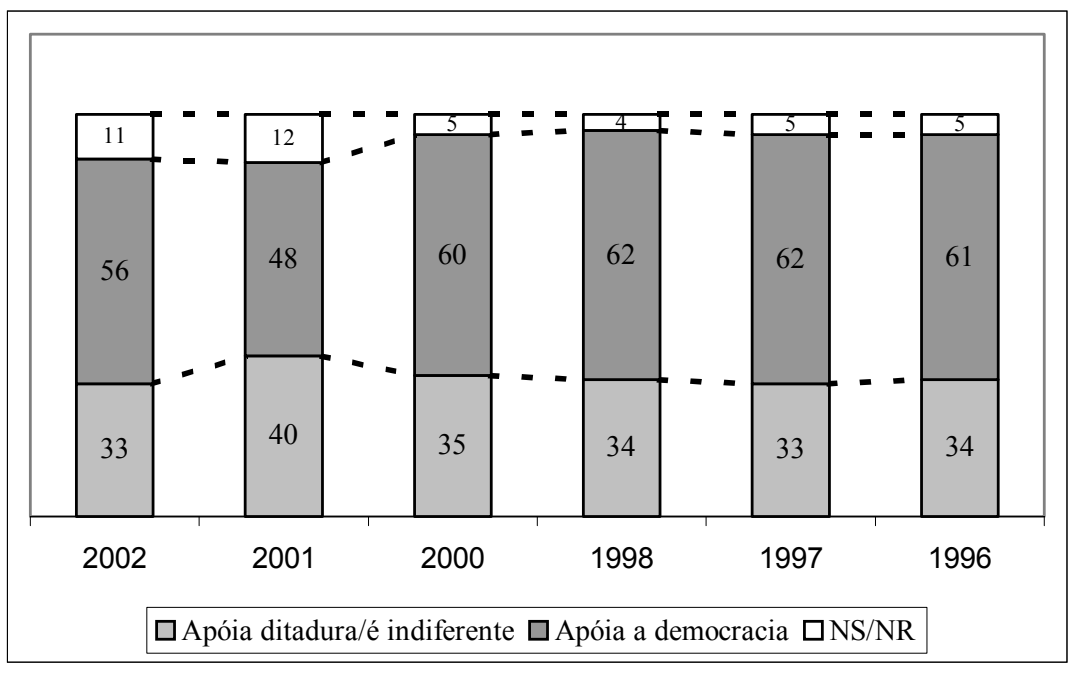

Fonte dos dados: Latinobarômetro, 2003.

Situações como estas vêm alimentando, nos últimos anos, tentativas de repensar a teoria da democracia desde um ângulo que visa, como afirmou Boaventura de Sousa Santos (2002), ampliar o cânone democrático. A partir desta perspectiva é possível destacar dois aspectos que analisaremos a seguir: o surgimento de uma crítica discursiva da democracia, desenvolvida especialmente por Jürgen Habermas; e a defesa de um modelo participativo de democracia embasado em algumas experiências inovadoras de gestão pública em nível local como, por exemplo, o orçamento participativo brasileiro. 


\section{As transformações comunicativas dos procedimentos democráticos}

O ponto de partida para compreender a aproximação de Jürgen Habermas ao debate sobre a democracia são os seus questionamentos sobre a validade da construção da imagem filosófica de mundo e a sua proposta de fundação de uma filosofia crítica questionadora da própria forma de existência da filosofia enquanto ciência, frente à perspectiva de superação da dicotomia entre teoria e práxis, tema decorrente das reflexões da Escola de Frankfurt (Jay, 1974, p. 139).

O mencionado autor busca recuperar o legado de uma tradição clássica das ciências sociais, cujo principal pilar é a obra de Max Weber, que, na transição entre o século XIX e as primeiras décadas do XX, transformaram o discurso crítico com relação ao capitalismo buscando incorporar as temáticas da ação social e da construção racional da realidade. Desde este prisma, Habermas amplia sua análise sobre as perspectivas das mudanças sociais através do questionamento à caracterização instrumental de modernização presente na teoria funcionalista e sua ênfase no desenvolvimento do mercado econômico como a única via para a evolução social.

Em sua tentativa de elaborar uma teoria alternativa capaz de superar o que chamou de legado não concretizado da Ilustração, o autor busca construir um modelo de interpretação social que resgata a centralidade da ação humana e o potencial que as estruturas comunicativas possuem para a superação das contradições da sociedade capitalista. Para tal fim, sugere a existência de quatro formas de ação social que sintetizam as diferentes possibilidades de intervenção social dos indivíduos: a ação teológica, na qual os fins justificam os meios; a ação regulada por normas, onde os comportamentos são pautados pelo conjunto de regras estipuladas pela sociedade; a ação dramatúrgica, através da qual os atores sociais dramatizam a sua própria existência; e a ação comunicativa, na qual o diálogo é o instrumento por meio do qual são construídos acordos em relação à ação.

Precisamente a defesa da ação comunicativa marcará a centralização da teoria social habermasiana ao redor dos problemas do diálogo e do consenso. Através desta ótica, a linguagem é elevada à condição de único instrumento pelo qual é possível, independente de quaisquer pré-requisitos, edificar con- 
sensos envolvendo a totalidade dos atores sociais. Como fruto deste processo, é construída uma racionalização comunicativa sustentada está baseada na idéia de descentração, conceito originalmente utilizado por Jean Piaget (1973) para descrever a etapa de desenvolvimento da inteligência da criança na qual ela passa a reger as suas atitudes baseando-se na sua relação com o mundo externo. No caso de Jürgen Habermas, tratar-se-ia da tentativa de legitimar a construção de uma visão de mundo através da interação com outros indivíduos e a sociedade em geral.

Buscando avaliar o significado desta nova concepção de ação social com base na construção de espaços discursivos, o citado autor considera que:

El logro más importante de tal enfoque es la posibilidad de clarificar un concepto de racionalidad comunicativa que escape a las trampas del logocentrismo occidental. En lugar de seguir el camino trazado por Nietzsche de una critica totalizadora y autorreferencial de la razón, bien sea a través de Heidegger hasta Derrida, o a través de Bataille hasta Foucault, y tirándolo todo por la borda, es mucho más prometedor intentar lograr esta finalidad a través del análisis del potencial operativo de la racionalidad que se encuentra contenido en la práctica cotidiana de la comunicación (Habermas, 1988, p. 312).

Assentado nesta percepção da realidade abalizada em procedimentos comunicativos, Jürgen Habermas propõe-se a discutir os principais problemas das teorias da democracia utilizando, como ponto de partida, a crítica a uma teoria normativa da democracia.

De acordo com a referida teoria, a estabilidade é a fonte de legitimidade do Estado, sendo que a garantia da ordem social reside, por um lado, na concordância e reconhecimento dos resultados eleitorais e das ações do governo pelos cidadãos, assim como na tolerância, por parte do governo, de qualquer ação advinda da sociedade que não represente uma ameaça violenta ao equilíbrio do Estado.

Partindo do princípio de que a autoridade governamental provém do poder das urnas, a concepção normativista toma como pressuposto a existência de um livre consentimento dos cidadãos que aceitam validar as ações decorrentes da adoção de determinadas opções eleitorais, representando a garantia do respeito das regras da delegação de poder outorgada aos setores ungidos pela eleição. 
Criticando esta perspectiva, Jürgen Habermas afirma que as teorias normativas da democracia são muito mais instrumentos de valorização ideológica da democracia liberal do que uma explicação plausível da adesão dos cidadãos à democracia e do funcionamento deste sistema. Neste sentido, para este autor, o elemento central não estaria na adesão voluntária direta do cidadão à política, mas nos procedimentos adotados com o fim de garantir que este processo se efetive. Frente à inadequação desta perspectiva de análise, uma alternativa poderia ser encontrada na discussão das teorias normativas da democracia que têm como núcleo a análise do processo de deliberação pública.

Caracterizando o processo de deliberação pública como o âmago do processo democrático, Jürgen Habermas sugere uma divisão entre uma perspectiva centrada em princípios liberais da democracia e outra nos princípios republicanos. Para compreender esta divisão é necessário sublinhar que:

Na perspectiva liberal, o processo democrático se realiza exclusivamente na forma de compromissos de interesses. E as regras de formação de compromissos, que devem assegurar a eqüidade dos resultados, e que passam pelo direito igual e geral ao voto, pela composição representativa das corporações parlamentares, pelo modo de decisão, pela ordem dos negócios, etc., são fundamentadas, em última instância, nos direitos fundamentais liberais. Ao passo que a interpretação republicana vê a formação democrática da vontade realizando-se na forma de um auto-entendimento ético-político, onde o conteúdo da deliberação deve ter o respaldo de um consenso entre os sujeitos privados, e ser exercitado pelas vias culturais; essa pré-compreensão socialmente integradora pode renovar-se através da recordação ritualizada do ato de fundação da república (Habermas, 1997, p. 18).

Sinteticamente, enquanto o modelo liberal de democracia pode ser entendido como uma proposta centrada na capacidade do Estado para mediar conflitos e administrar a sociedade desde o ponto de vista das necessidades do mercado econômico, a outra proposta, o modelo republicano de democracia, representa um projeto de construir um sistema político global centrado na capacidade de articulação da sociedade civil. ${ }^{7}$ Partindo destas premissas diferentes - Sociedade civil/Estado -, os modelos liberal e republicano apresentam distintas compreensões de três dimensões centrais para desenvolver a experiência democrática: a da cidadania; a do direito e a dos processos políticos (Habermas, 1995).

7 Bresser Pereira (2004) complementa esta diferenciação entre liberalismo e republicalismo enfatizando, entre outras questões, as divergências destes modelos em torno do problema dos direitos dos cidadãos e da definição de interesse público. 
Frente às diferenças entre os referidos modelos, Jürgen Habermas insta à formulação de uma terceira alternativa de organização política da sociedade que, incorporando diferentes elementos da teoria liberal e republicana, enfatize o processo através do qual o sistema político constrói novas formas de consenso fundamentadas numa teoria democrática discursiva. Da fusão entre liberais e republicanos o modelo discursivo absorve, dos primeiros, a estima à soberania do Estado e da normatização constitucional das relações políticas; no entanto, dos segundos, abarca a valorização da formação da opinião e da vontade pública, assim como a ênfase na capacidade de autodeterminação dos cidadãos.

De acordo com estas prerrogativas, Jürgen Habermas (2002, p. 280-281) sugere que, na sua proposta,

[...] a teoria do discurso conta com a intersubjetividade mais avançada presente em processos de entendimento mútuo que se cumprem, por um lado, na forma institucionalizada de aconselhamentos em corporações parlamentares, bem como, por outro lado, na rede de comunicação formada pela opinião pública de cunho político. Essas comunicações sem sujeito, internas e externas às corporações políticas e programadas para tomar decisões, formam arenas nas quais pode ocorrer a formação mais ou menos racional da opinião e da vontade acerca de temas relevantes para o todo social e sobre matérias carentes de regulamentação. A formação de opinião que se dá de maneira informal desemboca em decisões eletivas institucionalizadas e em resoluções legislativas pelas quais o poder criado por via comunicativa é transformado em poder administrativamente aplicável.

Tentando uma apreciação crítica das observações expostas no modelo habermasiano, é destacável o esforço que o autor realiza no sentido de construir um modelo de deliberação política eficiente que encurte distâncias entre o Estado e a sociedade civil. Além disso, é evidente o empenho do autor em tentar redimir os políticos profissionais e a atividade política em geral junto aos cidadãos, visando superar o desgaste evidente que as instituições públicas, os partidos políticos e as associações profissionais têm entre as maiorias politicamente desarticuladas da sociedade.

Entretanto, se em termos dos procedimentos o esquema comunicativo de Jürgen Habermas possui indubitáveis méritos, parece que o autor não leva às últimas conseqüências os efeitos de um chamamento aos cidadãos a participarem de espaços públicos de discussão, na medida em que os canais comunicativos tendem a cumprir uma função de pressão simbólica envolvendo os 
mecanismos de decisão do Estado e a formação de uma opinião pública coletiva. Conseqüentemente, mesmo com todos os espaços de diálogo possíveis, o poder de deliberação pública não troca de mãos, corresponde exclusivamente ao poder do Estado. ${ }^{8}$

Precisamente a ausência de uma reflexão mais apurada acerca das conseqüências dos procedimentos comunicativos sobre a distribuição do poder na sociedade acaba interferindo no modelo político habermasiano e sua frágil caracterização da cidadania. Isto fica evidente na argumentação do citado autor a respeito dos espaços comunicativos sobre os processos de deliberação política:

A teoria do discurso coloca em jogo uma outra idéia: para ela processos e pressupostos comunicativos da formação democrática da opinião e da vontade funcionam como comporta mais importante para a racionalização discursiva das decisões de um governo e de uma administração vinculados ao direito e à lei. $R a$ cionalização significa mais do que simples legitimação, porém menos do que a constituição do poder. O poder disponível administrativamente modifica a sua composição durante o tempo em que fica ligado a uma formação democrática da opinião e da vontade, a qual programa, de certa forma, o exercício do poder político. Independente disso, somente o sistema político pode "agir". Ele constitui um sistema parcial, especializado em decisões que obrigam coletivamente, ao passo que as estruturas comunicativas da esfera pública formam uma rede ampla de sensores que reagem à pressão de situações problemáticas da sociedade como um todo e estimulam opiniões influentes. A opinião pública, transformada em poder comunicativo segundo processos democráticos, não pode "dominar" por si mesma o uso do poder administrativo; mas pode, de certa forma, direcioná-lo [grifos meus] (Habermas, 1997, p. 23).

O impasse gerado pelo modelo comunicativo proposto por Jürgen Habermas, que reside na ausência de uma transição entre os procedimentos democrático-comunicativos e os de efetiva gestão do Estado, podem ser solucionados desde a ótica das teorias democrático-participativas que apresentam, em geral, projetos palpáveis de co-gestão do Estado envolvendo políticos profissionais e cidadãos.

8 A esse respeito sugiro ver a argumentação de Leonardo Avritzer (2000) em torno da questão da deliberação em Jürgen Habermas, assim como a de Sérgio Costa (1995) sobre a formulação da esfera pública. 
O surgimento de democracias participativas apresenta um eficiente antídoto para alguns dos principais problemas das democracias convencionais, na medida em que estas inserem processos anteriormente restritos aos círculos governamental e parlamentar na vida cotidiana dos cidadãos. A existência de diferentes níveis de reuniões que envolvem moradores das cidades e regiões, o estímulo aos debates sobre o espaço urbano, a participação nas determinações de obras públicas ou até mesmo a escolha, não de parlamentares, mas de vizinhos para fazerem parte de fóruns de gestão, representam não apenas uma mudança em termos da forma da democracia, como também uma verdadeira revolução no que diz respeito à constituição de capital social, entendido enquanto a formação de um conjunto de requisitos cívicos (cidadania, solidariedade, sentido público, coletivismo, etc.) que permitem o fortalecimento da organização da sociedade.

Esta é uma das grandes diferenças entre o modelo convencional de democracia e o participativo, já que enquanto no primeiro caso a participação restringe-se às urnas, no segundo há permanência de vínculos de relação entre o Estado, os cidadãos e a sociedade civil, o que permite a formação de laços sociais mais amplos do que aqueles gerados, apenas, pelos processos eleitorais.

\section{A perspectiva das democracias participativas}

Quando se fala em experiências de democracia participativa, uma primeira questão que vem à tona é a legitimidade da afirmação de uma variável tão específica deste regime político, considerando que adjetivar a democracia pode incorrer no deslocamento da compreensão do conceito na direção daqueles elementos - as adjetivações - que são periféricos ao seu entendimento. Contudo, no caso das recentes experiências de participação dos cidadãos na gestão pública (orçamento participativo, descentralização comunal, etc.), a noção de participação que está presente no conceito de democracia participativa acaba sendo o elemento central que nos permite compreender que tipo de democracia é esta, como ela se desenvolve e porque se diferencia frente a outras experiências semelhantes. 
Para sistematizar estas questões, meu ponto de partida é identificar alguns aspectos das concepções predominantes nos debates atuais sobre a questão democrática e que, em maior ou menor grau, são referenciadas nas contribuições de Giovanni Sartori, Robert Dahl e Norberto Bobbio. ${ }^{9}$ Partindo da caracterização que estes autores fazem da democracia, passo a analisar os pontos em comum e as diferenças que estas possuem com o modelo participativo.

Para Giovanni Sartori, a democracia pode ser considerada exclusivamente enquanto um regime político caracterizado pela delegação de poder dos cidadãos para os governantes, isto é, pelo processo através do qual os cidadãos elegem aqueles que irão representá-los na elaboração e administração das políticas do Estado. Como sublinha o mencionado autor:

En principio la democracia - la democracia liberal - ha de definirse como un sistema político basado sobre el poder popular, en el sentido de que la titularidad del poder pertenece al demos, mientras que el ejercicio del poder es confiado a los representantes periódicamente elegidos por el pueblo. Por consiguiente, en términos de ejercicio el poder popular se resuelve en gran medida en el poder electoral. [...] La democracia es un sistema pluripartidista en el que la mayoría expresada por la elecciones gobierna en el respeto a los derechos de las minorías (Sartori, 1994, p. 42).

É interessante, na caracterização anterior, como o autor vê com naturalidade o fato de que mesmo o cidadão sendo, como afirma, o "titular do poder", o mesmo deve manter o usufruto deste poder restrito à escolha de representantes de partidos políticos nos processos eleitorais periódicos, cabendo aos representantes eleitos traduzir ou apresentar a sua versão da vontade popular.

No caso de Robert Dahl (1989), mesmo chegando a conclusões que também reforçam a delegação de poder, o autor se esforça por apresentar uma definição de democracia mais ampla do que a sugerida por Giovani Sartori, centrando-se na satisfação de três aspectos: a possibilidade de o cidadão formular suas preferências; a garantia deste manifestar livremente estas preferências e seu direito a receber, por parte do governo, um tratamento equânime, indepen-

9 A escolha destes três autores como predominantes está baseada na análise de um conjunto de revisões bibliográficas sobre o tema da democracia que demonstram a centralidade da produção dos mesmos nesta questão. Sobre o tema ver, por exemplo Schmitter e Karl, 1994. 
dente das preferências que escolheu. Seguindo o mencionado autor, estes aspectos se desdobrariam em seis variáveis que representariam as principais condições para que a democracia fosse estabelecida. Estas seriam: liberdade de associação, expressão e de voto; livre competição entre os líderes políticos em busca de apoios e votos; existência de uma diversidade de fontes de informação; eleições livres e imparciais; elegibilidade para a coisa pública; existência de instituições que respeitem e garantam o poder das urnas.

Em especial, Robert Dahl avança naquilo que Giovanni Sartori havia deixado em suspenso, quer dizer, a formulação de uma série de mecanismos que ofereçam condições para que os cidadãos exerçam com plenitude todos os seus direitos políticos, fazendo com que a eleição seja um momento no qual estes possam livremente candidatar-se a cargos públicos ou escolher os seus representantes para os mesmos. Sobre o tema, como é conhecido, o autor emprega o conceito de poliarquia para classificar um modelo de democracia representativa centrada nos princípios do pluralismo e na existência de um sistema multipartidário competitivo.

Desde outra tradição teórica, Norberto Bobbio (1986, p. 84), da mesma forma que o autor anterior, também enfatiza a necessidade de indicar algumas normas claras que possibilitem a inclusão dos cidadãos no processo democrático, considerando que,

[...] se entiende por democracia un conjunto de reglas - las llamadas reglas del juego - que permiten la más amplia y más segura participación de la mayoría de los ciudadanos, ya en forma directa, ya en forma indirecta, en las decisiones políticas, o sea, a las decisiones que interesan a toda la colectividad.

De modo resumido, a determinação de normas democráticas que garantam uma gestão democrática do Estado estaria centrada em cinco questões básicas: o poder legislativo, os órgãos de administração local e os chefes de Estado devem ser instituídos através de procedimentos eleitorais diretos ou indiretos; todo o cidadão que tenha obtido maioridade legal deve ser considerado apto enquanto eleitor com reais garantias de liberdade de opinião e opção política; todo o voto deve ter peso igual, assim como o princípio da maioria numérica deve ser utilizado tanto para a eleição de representantes, quanto para as decisões dos órgãos públicos; garantias sobre os direitos das minorias; o governo deve gozar de confiança do Parlamento ou do chefe do poder executivo eleito pelos cidadãos (Bobbio, 1995, p. 327). 
Baseadas, fundamentalmente, na seleção de procedimentos que possam legitimar a proposta de democracia, as perspectivas adotadas pelos mencionados autores representam um ponto de partida importante para as reflexões atuais sobre as transformações no modelo democrático de gestão pública.

Enquadrando o modelo participativo nos esquemas propostos é perceptível que, sem grandes dificuldades, este atende ao conjunto dos requisitos considerados centrais para a caracterização de uma democracia e através dos quais os cidadãos possuem garantidos seus direitos de elaborar, manifestar e defender as suas convicções. Além disso, nas democracias participativas o Estado também se mantém regulado pelas normas constitucionais que prescrevem os direitos e deveres de todos os cidadãos, assim como existe uma subordinação às normas estabelecidas pela lei.

Contudo, a grande inovação dos modelos participativos, quando confrontados com os elementos que caracterizam as democracias formais, está em que, enquanto no âmbito representativo liberal o processo democrático fica restringido aos procedimentos, às normas do jogo democrático; na perspectiva participativa os procedimentos eleitorais são enriquecidos pela ênfase em, pelo menos, três novas dimensões.

A primeira dimensão é a da participação, do envolvimento dos cidadãos com a coisa pública. Rompendo com uma concepção tecnoburocrática de administração, a idéia de que os cidadãos devem ultrapassar a sua condição de eleitores para envolver-se no cotidiano da elaboração, execução e controle das políticas públicas revoluciona a idéia tradicional do Estado enquanto máquina burocrática e retoma a possibilidade de obtenção de legitimidade política através de novos canais de representação popular. A segunda é a da ênfase na deliberação pública, algo que interfere nas formas através das quais o governo elabora e executa suas políticas, assim como nas características que o Estado deve assumir para adequar-se a este modelo de gestão. Finalmente, a terceira é a valorização dos aspectos qualitativos do processo democrático, incorporando à questão dos procedimentos uma nova ênfase centrada na qualidade com a qual estes vêm sendo executados.

Em termos das transformações em nível das estruturas do Estado, não são poucos os autores que afirmam que uma mudança de fundo na democracia requer amplas modificações no modelo estatal predominante, ainda 
baseado na contraposição weberiana clássica entre o patrimonialismo e a burocracia. ${ }^{10}$ Nesta direção, Guillermo O’Donnell (1999, p. 580) enfatiza que "a democracia não deveria ser apenas analisada no plano do regime, mas também no do Estado", assim como também Manuel António Garretón (2003, p. 47), sublinha que o fortalecimento da democracia não poderia se dar apenas através da necessidade de "[...] completar as tarefas deixadas pendentes nas fundações, transições e reformas incompletas, mas [reconstruindo] a polis e os sistemas políticos, assim como [articulando] uma nova forma de relação entre o Estado, a política e os atores sociais".

Este debate, que envolve a discussão sobre a qualidade da democracia, é bastante recente e vem comparando as atenções de uma série de autores que, ao dedicar-se às análises sobre o desenvolvimento do regime político democrático pós-transições desde o autoritarismo, se deparam com a rápida perda de legitimidade de muitos governos eleitos e sua incapacidade, em vários casos, de implementar um programa consistente de defesa dos direitos humanos e desenvolvimento social.

Neste sentido, a proposição de um modelo democrático participativo no qual os cidadãos deliberam e controlam as políticas públicas conjuntamente com o Estado, significa um aperfeiçoamento do modelo democrático discursivo proposto originalmente por Jürgen Habermas na medida em que os canais comunicativos, representados nos diferentes tipos de fóruns de participação popular, desembocam num aprimoramento dos processos de decisão públicos e, conseqüentemente, fortalecem os cimentos de novas bases para a legitimação das ações do Estado.

Para entender melhor esta questão, é possível listar alguns elementos que caracterizam a formação das democracias participativas:

1) Existência de uma pré-disposição dos governantes para compartilhar com a sociedade civil os espaços de poder que correspondem à esfera do Estado;

2) criação de espaços de comunicação que articulem representantes da esfera estatal e da sociedade civil com o fim de estabelecer um canal de mediação entre os diferentes atores sociais;

10 A esse respeito, Weber, 1993, p. 1047-1117. 
3) constituição de uma agenda pública de discussões envolvendo a cidadania enquanto um todo ou seus representantes eleitos;

4) encaminhamento de deliberações previamente negociadas entre Estado e sociedade civil pelas estruturas estatais ou por mecanismos de co-gestão públicos.

Apesar de existirem diferentes variações de democracias participativas, o surgimento e a expansão deste modelo representaram uma das maiores transformações no regime político democrático desde a sua fundação, na medida em que não apenas coloca na ordem do dia a criação de mecanismos de inclusão política eleitoral, como também inova na geração de fórmulas administrativas que ampliam a participação dos cidadãos na gestão pública. Contudo, o principal ganho com este modelo participativo é a aproximação da democracia da vida cotidiana e sua inserção em novos espaços de convivências entre os cidadãos (o bairro, a escola, o clube, as moradias, etc.) que potencializam a discussão sobre a democratização de esferas extra-estatais.

\section{Avançando nos sentidos da democracia}

A discussão sobre um possível redimensionamento da democracia deve levar em conta recentes questionamentos no campo epistemológico que procuram inserir o debate político sobre o tema numa perspectiva ampliada de transformação social. ${ }^{11}$

Localizando esta polêmica no campo das ciências humanas e sociais, é possível afirmar que estamos assistindo não só uma crise dos conceitos que tradicionalmente nos auxiliavam a compreender o social, um "esbater dos contornos das categorias que pareciam estruturar as relações sociais" (Hespanha, 2002, p. 164), mas também uma crise dos paradigmas que pautaram os modelos sociais da modernidade, considerando que "já não se trata mais [...] da sociedade nacional ou do Estado-nação, trata-se também e principalmente da sociedade mundial" (Ianni, 1999, p. 23).

11 Um exemplo deste debate pode ser encontrado em J. Butler, E. Laclau e S. Zizek, 2000. 
Estas mudanças igualmente podem ser observadas no que diz respeito aos estudos sobre a democracia, um dos temas centrais da sociologia e ciência política, que passam por um momento de redefinição de muitos dos seus parâmetros teóricos e práticos (Schmitter e Karl, 1994; Santos e Avritzer, 2002.). A esse respeito, Boaventura de Sousa Santos é contundente ao afirmar que a democracia não pode ficar restrita ao Estado, sendo necessário também democratizar a esfera não-estatal, considerando que apenas com a convergência entre diferentes arenas de democratização será possível construir um espaço público de deliberação democrática.

Mesmo havendo distintos nuances nas argumentações que contribuem para essa discussão, algo perfeitamente aceitável desde as diferentes perspectivas teóricas adotadas, é possível observar uma convergência ao redor de um conjunto de aspectos básicos que identificariam uma nova vertente de análise. Entre as diferentes características desta mudança de orientação sugiro destacar cinco aspectos:

a) A percepção da democracia enquanto uma experiência dimensionada espaço-temporalmente, o que dificultaria transpassar modelos bem sucedidos de uns países para outros;

b) a caracterização da democracia como um modelo que vai além do regime político, envolvendo o Estado, a sociedade e os seus sub-sistemas (jurídico, cultural, educacional, etc.);

c) a ênfase na mediação entre o local e o global, assim como das esferas sub-nacionais, enquanto um redimensionamento dos fatores que condicionam a estabilidade política;

d) a incorporação de novas problemáticas que interferem na abordagem da democracia, como as relações homens/mulheres, a etnia, a sustentabilidade, a cultura política, etc.

e) a valorização das condições societárias de desenvolvimento da democracia, como os aspectos vinculados aos direitos humanos, capital social, violência, desemprego, entre outros.

O surgimento de uma nova perspectiva de análise da democracia que, como enfatiza Guillermo O’Donnell (1999, p. 577-580), diferencia-se da abordagem tradicional do tema, recebe um impulso decisivo gerado pelas 
próprias condições atuais de existência deste sistema. Consideradas, após a simbólica queda do Muro de Berlim (1989), como as alternativas soberanas de organização política dos países na esfera mundial, as democracias ocidentais estão sofrendo as conseqüências do avanço da globalização e sua interferência na governabilidade dos Estados nacionais, assim como o impacto do que uma parcela da literatura especializada vem chamando de distanciamento entre os cidadãos e os seus governantes: total indiferença, desinteresse pela política estatal, pelos partidos políticos, e, principalmente, pela ação dos políticos profissionais (Putnan, Pharr e Dalton, 2000; Torcal, 2001).

O interessante é que ao mesmo tempo em que isto acontece, também existe uma novíssima ressurreição da sociedade civil. Esta expressão, utilizada principalmente a partir das análises de Guillermo O'Donnell e Philippe Schmitter (1988), serviu para descrever o processo, vivido entre a segunda metade dos anos setenta e a década de oitenta, a partir do qual a sociedade civil de países governados por ditaduras no sul da Europa e América Latina saiu às ruas para exigir a mudança de regime. Atualmente, estaríamos vivendo uma nova fase deste processo, especialmente nos países ocidentais democráticos, na qual a mobilização cidadã não visa uma ruptura com o regime, mas almeja fundamentalmente ganhos para a coletividade, como a recuperação de espaços públicos (praças, escolas, ruas), o aprimoramento de serviços sociais e a melhoria da qualidade de vida da comunidade.

As políticas alternativas no campo da democracia fluem pelos mesmos canais e utilizam tecnologias semelhantes às empregadas pelo mercado internacional de capitais, através de infovias mundiais. Em poucos segundos, qualquer cidadão que possua um computador conectado à internet e conhecimentos básicos de informática, tem acesso a informações privilegiadas sobre os mais diferentes assuntos políticos, como também condições de participar dos mais diversos tipos de articulação através de verdadeiras redes de ações sociais. Cabe lembrar que a internet tem sido o canal privilegiado de conexão de todas as grandes manifestações antiglobalização que ocorreram nos últimos anos e representa um ágil instrumento de articulação social. 
De um modo geral, estas políticas não são uniformes. Algumas são executadas pelas mãos do Estado através de gestões administrativas vinculadas, principalmente, a movimentos com origens diversas que visam uma renovação da esquerda (cristãos, marxistas, social-democratas, etc.). Outras são frutos exclusivamente da iniciativa da sociedade civil e das transformações geradas pelos movimentos sociais de novo tipo, principalmente o terceiro setor e as ONGs, que articulam vontade política com capacitação técnica. Contudo, ambas as vias possuem como elo de ligação o fato de colocarem o cidadão no centro do processo político de gestão pública, abrindo um espaço considerável para a ampliação das pautas da democracia envolvendo desde novas formas de produção econômica, como as economias solidárias, até mudanças no campo das relações interpessoais e da intimidade, baseadas no respeito mútuo e na solidariedade. ${ }^{12}$

Como já enfatizou Jürgen Habermas (1997, p. 30), o fato de o cidadão ser também responsável pela co-gestão do Estado tem implicações que ultrapassam a esfera das relações políticas na medida em que fortalecem o tecido de articulações entre os próprios cidadãos e colocam na pauta das discussões questões que, mesmo sendo originárias da esfera privada, interferem no modo de vida da coletividade.

\section{Considerações finais}

Iniciei este artigo debatendo as limitações de um sistema democrático restrito ao processo eleitoral, que foi o abre-alas para as discussões a respeito do aperfeiçoamento dos procedimentos de deliberação democrática sustentado nos argumentos habermasianos sobre as mediações dos processos comunicativos. Em prosseguimento abordei aquilo que considerei uma conseqüência desta perspectiva, a possibilidade de ampliação do processo de deliberação democrática, cerne da defesa dos modelos democráticoparticipativos de gestão. Na continuidade, fiz algumas observações sobre o potencial da democracia deixar de ser somente um regime político democrático para passar a ser um modelo social.

12 Este é um tema especialmente explorado por Anthony Giddens que, em diversas obras se refere à democratização dos sentimentos ou da intimidade. Sobre isso, sugiro especialmente Giddens, 1992. 
Para finalizar, considero importante sublinhar a centralidade do debate sobre a democracia, que trás consigo dois temas que são vitais para o desenvolvimento das nossas sociedades: a polêmica sobre o futuro do capitalismo e a possibilidade de germinarem alternativas a este modelo social. Com isto quero dizer que no mesmo instante em que qualquer pessoa dialoga sobre a democracia, não só se está referindo ao modelo de sociedade que tem, mas também ao modelo de sociedade que deseja ter.

Esta abrangência nem sempre é muito clara, até porque quando se fala em democracia, geralmente, o que muitos querem dizer é regime político democrático, enfim, uma forma de governo baseada em prerrogativas básicas que, pelo menos na teoria, todos conhecemos.

Como argumentei no transcorrer deste trabalho, nossa compreensão deste tema não precisa ficar restrita a isso. Todavia, esta não é uma mudança fácil, pois ampliar a abrangência dos usos da democracia interfere em aspectos da vida social que envolvem relações patriarcais, religiosas, culturais, em resumo, formas de dominação que vão além da esfera política e sobre as quais nem todos os cidadãos têm o desejo de interferir.

\section{Referências}

AVRITZER, Leonardo. Teoria democrática e deliberação pública. Lua Nova, São Paulo, n. 50, 2000.

BECK, Ulrich. Risk society. Towards a new modernity. Londres: Sage, 1992.

BEINSTEIN, Jorge. Capitalismo senil. Rio de Janeiro: Record, 2001.

BOBBIO, Norberto. Democracia. In: BOBBIO, Norberto; MATEUCCI, Nicola; PASQUINO, Gianfranco (Orgs.). Dicionário de política. Brasília: UnB, 1995.

¿Qué socialismo? Barcelona: Plaza \& Janés, 1986.

BRESSER PEREIRA, Luis Carlos. O surgimento do Estado Republicano. Lua Nova, São Paulo, n. 62, 2004.

BUTLER, Judith; LACLAU, Ernesto; ZIZEK, Slajov. Contingency, hegemony, universality. Londres: Verso, 2000.

COSTA, Sérgio. A democracia e a dinâmica da esfera pública. Lua Nova, São Paulo, n. 36, 1995.

CHERENSKY, Isidoro; POSADELA, Inés (Org.). Politica e instituciones en las nuevas democracias. Buenos Aires: Paidós, 2001. 
DAHL, Robert. La poliarquía. Barcelona: Paidós, 1989.

ERIKSON, Eric. Identidade, juventude e crise. Rio de Janeiro: Guanabara, 1987.

FORRESTER, Vivianne. Uma estranha ditadura. São Paulo: Unesp, 2001.

GARRETÓN, Manuel Antonio. Democratización y nuevas relaciones Estadosociedad en América Latina. In: GARRETÓN, Manuel Antonio; GUGLIANO, Alfredo Alejandro (Orgs.). La democracia en las Américas. Pelotas: Educat, 2003.

GASPARD, Michel. Revenus et niveau de vie en Europe centrale et orientale et en exURSS. Le Courrier des Pays de l'Est. Paris, n. 383, oct. 1993.

GIDDENS, Anthony. Mundo em descontrole. Rio de Janeiro: Record, 2000.

—. A transformação da intimidade. São Paulo: Unesp, 1992.

GUGLIANO, Alfredo Alejandro. A crise política como solução? Revista Brasileira de Estudos Constitucionais, São Paulo, n. 3, jan.-jun. 2004.

HABERMAS, Jürgen. A inclusão do outro. Estudos de teoria política. São Paulo: Loyola, 2002.

. Direito e Democracia. São Paulo: Tempo Brasileiro, 1997. 2 v.

— Três modelos normativos de democracia. Lua Nova, Sao Paulo, n. 36, 1995.

. Cuestiones y contracuestiones. In: BERNSTEIN, Richard (Org.). Habermas y la modernidad. Madrid: Cátedra, 1988.

HELD, David; McGREW, Anthony. Prós e contras da globalização. Rio de Janeiro: Zahar, 2000.

HESPANHA, Pedro. Mal-estar e risco social num mundo globalizado: novos problemas e novos desafios para a teoria social. In: SANTOS, Boaventura de Sousa (Org.). A globalização e as ciências sociais. São Paulo: Cortez, 2002.

HUNTIGTON, Samuel. La tercera ola. Barcelona: Paidós, 1994.

IANNI, Octávio. A sociologia e as questões sociais na perspectiva do século XXI. In: SANTOS, José Vicente Tavares dos; GUGLIANO, Alfredo Alejandro (Orgs.). $A$ sociologia para o século XXI. Pelotas: SBS/Educat, 1999.

JAY, Martin. La imaginación dialéctica: una historia de la Escuela de Frankfurt. Madrid: Taurus, 1974.

LATINOBARÓMETRO. Informe de Prensa 2003. Santiago de Chile: Latinobarómetro, 2003.

MARCUSE, Herbert. Ideologia da sociedade industrial. Rio de Janeiro: Zahar, 1967.

MARX, Karl. Contribuição para a crítica da economia política. Lisboa: Estampa, 1977. 
O'DONNELL, Guillermo. Teoria democrática e política comparada. Dados, Rio de Janeiro, v. 42, n. 4, p. 577-654, 1999.

; SCHMITTER, Philippe. Transiciones desde un gobierno autoritário. Conclusiones tentativas sobre las democracias inciertas. Barcelona: Paidós, 1988.

PIAGET, Jean. Escritos sociológicos. Rio de Janeiro: Forense, 1973.

PINTOR, Rafael; GRATSCHEW, Maria. Voter turnout since 1945. Estocolmo: International IDEA, 2001.

PUTNAN, Robert; PHARR, Susan; DALTON, Russell. What's Troubling the Trilateral Democracies? In: PUTNAN, Robert; PHARR, Susan (Ed.) Disaffected democracies. Princenton: Princenton University Press, 2000.

RIBEIRO, Renato Janine. Sobre o voto obrigatório. In: BENEVIDES, Maria Victória et al. (Org.). Reforma política e cidadania. São Paulo: Instituto da Cidadania, 2003.

SANTOS, Boaventura de Sousa; AVRITZER, Leonardo. Para ampliar o cânone democrático. In: - . (Org.). Democratizar a democracia. Rio de Janeiro: Civilização Brasileira, 2002.

SARTORI, Giovanni. A teoria da democracia revisitada. São Paulo: Ática, 1994. 2 v.

SCHMITTER, Philippe; KARL, Terry L. The conceptual travels of transitologist and consolidogist: how far to the East should they attempt to go? Slavic Review, n. 63, p.173-185, 1994.

SCHUMPETER, Joseph A. Capitalism, socialism and democracy. Nova York: Harper \& Brothers, 1963.

SEN, Amartya. Desenvolvimento como liberdade. São Paulo: Companhia das Letras, 2000.

TILLY, Charles. Coerción, capital y los Estados europeos. Madri: Alianza, 1992.

TORCAL, M. La desafección en las nuevas democracias del sur de Europa y Latinoamérica. Instituciones y Desarrollo, p. 8-9, may 2001.

WEBER, Max. Estado y sociedad. México: FCE, 1993. 